\title{
Binge Drinking and Antisocial and Unlawful Behaviours in Australia
}

Ou Yang, Xueyan Zhao and Preety Srivastava

This paper presents individual-level evidence from Australia to examine the factors associated with binge drinking and several alcohol-related antisocial and unlawful behaviours. We study in particular the role of binge drinking in increasing the likelihood for engaging in these negative behaviours. We use individual-level data from a national representative survey and a system econometric model that allows unobservable factors for all negative behaviours to be correlated. Potential misclassification of individuals' drinking pattern is accounted for. We find evidence of under-reporting for bingeing and significant effects of binge drinking on drink driving, physical and verbal abuse, public disturbance and stealing and damaging properties.

Keywords: Binge drinking; alcohol abuse and violence; drink driving; multivariate probit; endogeneity; misclassification.

JEL classification: C3, I1, K3

Ou Yang

Melbourne Institute of Applied Economic and Social Research, University of Melbourne, Australia.

E-mail: Ou.Yang@unimelb.edu.au

Xueyan Zhao (corresponding)

Department of Econometrics and Business Statistics, Monash University, Australia.

Tel +61 399052415 .

E-mail Address: Xueyan.Zhao@monash.edu 


\section{Introduction}

Binge drinking and its related adverse effects have long been one of the major policy concerns in many countries. Although there has been evidence showing that moderate alcohol consumption benefits health among middle-aged and older people (for example Gaziano, Buring, and Breslow 1993, Rimm 1996, Fagrell, Faire, and Bondy 1999, and Malinski et al. 2004), the toll taken by excessive alcohol consumption or binge drinking on many societies significantly overtakes the benefit from moderate consumption. For instance, alcohol harm was responsible for $3.2 \%$ of the total burden of disease and injury in Australia in 2003, while the benefit prevented $0.9 \%$ per cent of the total burden (Begg et al. 2007).

Like in many other developed countries, alcohol consumption is inherent in the Australian culture. However, recent statistics show that consumption of alcohol at harmful levels in Australia is considerable. According to the 2010 Australian National Drug Strategy Household Survey (AIHW 2011), around 39.8\% Australian people who are 14 years or older drank at least once in the previous 12 months (on a single drinking occasion) to an extent that put them at risk of an alcohol-related injury. Much of the recent concern arises from the evidence of a bingeing epidemic and an increasing popularity of pre-mixed ready-to-drink (RTD) spirits, especially among youth and young adults. In 2010, almost two-thirds (64.6\%) of males aged 18-19 years, and more than half (54.9\%) of males aged 20-29 years placed themselves at risk of an alcohol-related injury at least once a month (AIHW 2011). In this context, evidence from Australia and its on-going experience in addressing the alcohol abuse epidemic is an interesting case study.

In addition to education and regulation, one of the main policy tools used by governments around the world for reducing alcohol abuse is alcohol taxation. Excessive 
alcohol consumption is associated with a range of negative externalities in areas of road accidents, criminal activities, abuses of family members and others, health care, law enforcement costs, and some labour market participation and productivity implications (Freebairn 2010). These external costs are often not included as private costs in a consumer's personal consumption decision making and are borne by the society. Whilst attempts to separately estimate the private and public costs of alcohol abuse are controversial (Manning et al. 1989; Richardson and Crowley 1997; Freebairn 2010), there is no doubt that the extent of market failure is substantial. The key rationale for alcohol tax is to correct market failure by reducing excessive consumption that induces high external social costs. Thus, quantifying the associated harm to the society from excessive alcohol consumption is a necessary step in formulating alcohol related policies.

Drinking can increase the probability of people participating in behaviours that are antisocial, harmful or even criminal. For example, excessive alcohol consumption can lead to risky sexual activities and violent behaviours. On the other hand, alcohol consumption in conjunction with normal activities, such as driving or swimming while under the influence of alcohol, can increase the probability that such activities result in harm. Some studies have looked at the link between alcohol drinking patterns and alcohol-related antisocial behaviours using both population- and individual-based data and methods. Specifically, incidences of alcohol-related antisocial behaviours have been compared across different populations (for example, Zetola et al. 2014, Umana and Adeoye 2014, Lane et al. 2008, Weiser et al. 2006, Douglas et al. 1997, Wechsler et al. 1994). Individual-based studies, on the other hand, have examined the correlation between individual alcohol-drinking patterns and incidence of alcohol-related antisocial or risky behaviours. They have found that heavy drinkers are more likely to participate in risky activities or undertake anti-social and unlawful behaviours (for 
example Bègue et al. 2012, Petrie et al. 2010, Beck, Fell, and Yan 2009, Greenfield and Weisner 1995, Cherpitel 1995).

To the best of our knowledge, drinking patterns have mostly been treated as exogenous in this literature (see, for example, Brown and Vanable 2007, Markowitz, Kaestner, and Grossman 2005, Salomé et al. 2005, Greenfield and Weisner 1995). However, individuals' drinking patterns and their inclination towards antisocial behaviours under the influence of alcohol are very likely to be driven by a common set of unobservable factors. Thus, it may be inappropriate to treat drinking patterns as exogenous. For instance, as Gottfredson and Hirschi (1990) argued in their book, people who lack self-control are more likely to engage not only in antisocial or unlawful activities, but also negative behaviours such as drinking, gambling and smoking. In addition, some other personality traits linked to individuals' differences in behaviours, such as impulsiveness, risk-taking and sensation-seeking, are also believed to be related to alcohol use and abuse (Cherpitel 1993). Such confounding factors can potentially obscure the extent of correlations and induce endogeneity or simultaneity bias (Hayashi 2000). Exceptions in this literature are Chatterji et al. (2004) and Sen (2002), both of which used a recursive bivariate probit model to deal with endogeneity. However, they did not fully take the advantage of the system approach to discuss all results of interest.

This paper aims to contribute to this growing body of literature by studying the association of binge drinking with alcohol-related antisocial and unlawful behaviours, using a nationally representative individual-level dataset in Australia. We make several specific contributions to this empirical literature. We allow for the endogeneity of binge drinking behaviour in its association with negative behaviours and use alcohol price variation as instrumental variable to identify the endogenous treatment effect. We also consider several negative alcohol related behaviours separately rather than focusing on a single crime alone as 
in most of the existing studies. We use a system approach with a multivariate probit model to allow for unobservable factors for all negative drinking behaviours to be correlated. In addition, as the self-reported drinking pattern variable is potentially subject to misclassification, we also explicitly allow for possibilities of misclassification using a modified maximum likelihood approach following Hausman, Abrevaya, and Scott-Morton (1998). Finally, our results provide useful evidence to contribute to the limited empirical literature in both Australia and overseas on the association between binge drinking and antisocial and unlawful behaviours.

The rest of this paper is set out as follows. Section 2 details the data. Section 3 presents the econometric framework. The estimation results are discussed in Section 4, and Section 5 concludes this paper.

\section{Data}

The data we use in this study are drawn from the 2001, 2004, 2007 and 2010 waves of the Australian National Drug Strategy Household Survey (NDSHS), involving 106,193 individuals (NDSHS 2010). The NDSHS is a nationally representative cross-sectional survey of the non-institutionalized Australian civilian population aged 12 years and older and is administered by the Australian Institute of Health and Welfare (AIHW). The survey provides information on drug use patterns, attitudes and behaviour. It also provides a wide range of information on respondents' demographic and socioeconomic backgrounds.

Key to our study is information on individuals' antisocial behaviours that they had undertaken under the influence of alcohol. In the survey, information on individuals' antisocial behaviours is collected via a question asking "In the last 12 months, did you undertake the following while under the influence of or affected by alcohol?" The 
respondents then tick "Yes" or "No" for each of the following activities: "Went to work", "Went swimming", "Operated a boat", "Drove a motor vehicle", "Operated hazardous machinery", "Created a public disturbance or nuisance", "Caused damage to property", "Stole money, goods or property", "Verbally abused someone" and "Physically abused someone".

In this paper, we focus on the following antisocial and unlawful behaviours: "Drove a motor vehicle", "Created a public disturbance or nuisance", "Caused damage to property", "Stole money, goods or property", "Verbally abused someone" and "Physically abused someone". Table 1 displays the proportions of individuals in the sample who participated in each of these antisocial behaviours while under the influence of alcohol, across waves of survey from 2001 through 2010.

For practical purposes, we categorise the activities into three groups. Given similarities among some of these behaviours, a natural manner of grouping would be: Driving (drove a motor vehicle), Disturbance (created a public disturbance/nuisance or caused damage to property), Stealing (stole money, goods or property), and Abuse (verbally or physically abused someone). However, as can be seen in Table 1, compared to other groups, the percentage of the sample in the Stealing group is rather small. We therefore merge this group with the Disturbance group. Consequently, this combined group includes both Disturbance and Stealing.

Table 2 depicts the proportions of sub-groups of individuals in the sample who participated in each of the three groups of antisocial behaviours while under the influence of alcohol, conditioned on age, gender and waves of survey from 2001 through 2010. Throughout these four waves of survey, participation rates of drink driving dominate for both male and female across all the age groups except 12-17, who usually do not have a full 
licence and to whom substantial restrictions to driving apply in Australia. Clearly, Disturbance and Abuse show a declining trend, but the proportions are still quite significant, especially for youth and young adults. The decline in drink driving for the 18-22 group may also reflect the effectiveness of the introduction of longer probation period and zero alcohol tolerance policy for probationary drivers. We also see that in all age groups ranging from 1822 to the $60+$, male drinkers tend to be more likely to participate in all the three types of antisocial behaviours than female drinkers, while under the influence of alcohol. In contrast, female drinkers in the 12-17 age group who were surveyed in the years of 2004 and 2010 are more likely to have verbally or physically abused someone than male drinkers from the same age group surveyed within the same year.

In this study, drinkers are defined as those who have consumed alcohol in the past year and the rest are defined as abstainers. This results into a sub-sample of 82,053 drinkers. The harmful consequences pertaining to alcohol consumption are generally linked with heavy or binge drinking. Not only does binge drinking, especially among adolescents and young adults, result in a high incidence of vehicle crashes, crime and violence, but it also has detrimental and often irreversible consequences in terms of health, human capital and social status.

Binge drinking is generally recognised as drinking heavily on an occasion; however, its definition has been controversial. The definition disagrees on, among others, the units of measurement of alcohol beverages and the number of drinks. In the absence of a unified measurement of binge drinking, in this study risk levels related to short-term harm of drinking, as defined in the 2001 National Health and Medical Research Council Alcohol Guidelines (NHMRC 2001), are used to group drinkers by different drinking patterns. Therefore, bingers are defined as those who have engaged in medium-to-high-risk drinking in the past year: specifically, men drinking at least seven standard drinks and women drinking at 
least five standard drinks on a single occasion. This definition of binge or heavy drinking has also been adopted in several other studies on binge drinking (for example Chaloupka and Wechsler 1996, Williams, Chaloupka, and Wechsler 2002, Srivastava and Zhao 2010). ${ }^{1,2}$

We define individuals as bingers based on the survey question where they were asked to report their drinking patterns in the last 12 months. Specifically, the following question was asked: "Please record how often in the last 12 months you have had each of the following number of standard drinks in a day?" Respondents had to then choose from a grid with the vertical array displaying the number of standard drinks such as "20 or more drinks", "11-19 standard drinks" to "less than 1 standard drink" or "none", and the horizontal array displaying the frequency such as "everyday", "5 to 6 days a week" to "about once a month", "less often" or "never". A snapshot of this question is given in Figure A1 in the supplementary online appendix.

On the basis of the 2001 National Health and Medical Research Council Alcohol Guidelines, if a man has ever, even if the frequency is "less often" (see Figure A1), found himself associated with any of the three drinking scenarios: "7-10 standard drinks a day", "11-19 standard drinks a day" and "20 or more standard drinks a day", he is defined as a binger engaging in medium-to-high-risk drinking; if a woman has ever, even if the frequency is "less often" (see Figure A1), found herself associated with any of the four drinking scenarios: "5-6 standard drinks a day", "7-10 standard drinks a day", "11-19 standard drinks a

\footnotetext{
${ }^{1}$ In March 2009, the NHMRC released a new set of guidelines on alcohol consumption and health risks. However, this new set of guidelines is controversial in that although, in recognition of the fact that the lifetime risk of harm from consuming alcohol increases progressively with the amount consumed (NHMRC 2009), the previous threshold-based definitions for risky or high-risk drinking were removed. In particular, the 2009 guidelines recommend that drinking no more than two standard drinks, for both men and women, on any day reduces the lifetime risk of harm from alcohol-related disease or injury. To conform to the definition of binge drinking conventionally used in previous studies we follow the 2001 guidelines.

${ }^{2}$ We have also re-run our model to the alternative definition of binge drinking, which only represents high-risk drinking pattern. It shows that our results are generally robust against this alternation definition. The full results are available from the authors upon request, given the limited space of this paper.
} 
day" and "20 or more standard drinks a day", she is defined as a binger engaging in mediumto-high-risk drinking.

In Table 3, we see that most of the respondents (about 80\%) from each wave of the survey are drinkers and around $30-35 \%$ are bingers. For obvious reasons, in this study drinkers and bingers are of principal interest to us. The observed unconditional correlation coefficients between the antisocial behaviours undertaken under the influence of alcohol and drinking pattern are presented in Table A1 in the supplementary online appendix. From this preliminary result it is clear that drinking pattern (binge or not) is correlated with alcoholrelated antisocial behaviours.

In our econometric model, we control for a range of individual socioeconomic, demographic and lifestyle factors, as well as (aggregated) alcohol price. Details on all dependent and explanatory variables used in this study are presented in Table A2 and Table A3 in the supplementary online appendix.

\section{Econometric Framework and Estimation Issues}

To jointly study the association between binge drinking and the alcohol-related antisocial behaviours, we specify a system of probit equations with a triangular endogenous structure $^{3}$, which allows binge drinking to be determined endogenously. Let $Y_{i, B}^{*}, Y_{i, \text { Driving }}^{*}$, $Y_{i, \text { Disturbance }}^{*}$ and $Y_{i, \text { Abuse }}^{*}$ denote the propensity of the $i^{\text {th }}$ individual in the sample to participate in binge drinking and the three alcohol-related antisocial behaviours. The four latent variables are mapped to observed binary dummy variables $Y_{i, B}, Y_{i, \text { Driving }}, Y_{i, \text { Disturbance }}$ and $Y_{i, A b u s e}$ using:

\footnotetext{
${ }^{3}$ For a similar bivariate case, see Greene (2007 p. 823) and Maddala (1983 p. 123).
} 


$$
Y_{i, L}=\left\{\begin{array}{l}
1 \text { if } Y_{i, L}^{*}>0 \\
0 \text { if } Y_{i, L}^{*} \leq 0
\end{array}\right.
$$

where $L \in\{B$, Driving, Disturbance, Abuse $\}$, and $Y_{i, L}=1$ to indicate participation and $Y_{i, L}=0$ otherwise.

We specify the system of equation as follows:

$$
\left\{\begin{array}{l}
Y_{i, B}^{*}=X_{i, B}^{\prime} \beta_{B}+\varepsilon_{i, B} \\
Y_{i, \text { Driving }}^{*}=X_{i, \text { Driving }}^{\prime} \beta_{\text {Driving }}+\alpha_{\text {Driving }} Y_{i, B}+\varepsilon_{i, \text { Driving }} \\
Y_{i, \text { Disturbance }}^{*}=X_{i, \text { Disturbance }}^{\prime} \beta_{\text {Disturbance }}+\alpha_{\text {Disturbance }} Y_{i, B}+\varepsilon_{i, \text { Disturbance }} \\
Y_{i, \text { Abuse }}^{*}=X_{i, \text { Abuse }}^{\prime} \beta_{\text {Abuse }}+\alpha_{\text {Abuse }} Y_{i, B}+\varepsilon_{i, \text { Abuse }}
\end{array}\right.
$$

where $X_{i, B}^{\prime}, X_{i, \text { Driving }}^{\prime}, X_{i, \text { Disturbance }}^{\prime}$ and $X_{i, \text { Abuse }}^{\prime}$ are vectors of exogenous covariates. The error terms in the respective equations are assumed to independently and identically follow a multivariate normal distribution with mean zero and covariance matrix $\Sigma$; that is $\left(\varepsilon_{i, B}, \varepsilon_{i, \text { Driving }}, \varepsilon_{i, \text { Disturbance }}, \varepsilon_{i, \text { Abuse }}\right)^{\prime} \sim \operatorname{MVN}(0, \Sigma)$, where

$$
\sum=\left(\begin{array}{cccc}
1 & \rho_{B, \text { Driving }} & \rho_{B, \text { Disturbance }} & \rho_{B, \text { Abuse }} \\
\rho_{B, \text { Driving }} & 1 & \rho_{\text {Driving,Disturbance }} & \rho_{\text {Driving,Abuse }} \\
\rho_{B, \text { Disturbance }} & \rho_{\text {Driving,Disturbance }} & 1 & \rho_{\text {Disturbance,Abuse }} \\
\rho_{B, \text { Abuse }} & \rho_{\text {Driving,Abuse }} & \rho_{\text {Disturbance,Abuse }} & 1
\end{array}\right) .
$$

We assume $\operatorname{Var}\left(\varepsilon_{i, L}\right) \equiv 1(L \in\{B$, Driving,Disturbance, Abuse $)$ in order for the parameters to be identified separately from the variance of $\varepsilon$ (Greene 2007). Equations (1) - (3) together specify an endogenous multivariate probit (MVP) system model with a recursive simultaneous structure that jointly determines the binge drinking decision and the three decisions to participate in antisocial behaviours while under the influence of alcohol. Specifically, the MVP specification with potentially non-zero off-diagonal elements in $\Sigma$ allows for correlations across the disturbances of the four latent equations. Note that when the 
off-diagonal elements in $\Sigma$ equal zero the MVP model reduces to four independent probit models which can then be estimated separately.

Identification is a major concern when estimating systems of equations. Although identification can be achieved under the assumed data generating process (DGP) of multivariate normal distribution due to the non-linearity of the MVP model, Li, Poskitt, and Zhao (2014) show that, under the partial identification framework where the true DGP is allowed to be a broader class beyond a MVP, the existence of instrumental variables is crucial for narrowing the confidence bounds for average treatment effects. Monfardini and Radice (2008) also show that even if the distribution of errors is mis-specified exclusion restriction preserves the validity of the inference in finite sample. So, besides relying on the functional form of the MVP for identification in the asymptotics, we follow the literature and impose exclusion restrictions to enhance identification under more robust assumptions. Specifically, $X_{i, B}$ need to contain instrument(s) which do not appear in $X_{i, \text { Driving }}^{\prime}$, $X_{i, \text { Disturbance }}^{\prime}$ and $X_{i, \text { Abuse }}^{\prime}$.

In the literature a wide range of variables have been used to instrument the use of drugs such as tobacco, alcohol, marijuana, cocaine (see French and Popovici 2011 for a detailed survey of various instruments). Typical instruments for alcohol consumption include family characteristics, e.g. parent with alcohol problems and parent's smoking status (Koch and McGeary 2005, Renna 2007, French and Maclean 2006); personal beliefs/characteristics, e.g. religiosity, smoked at age 18, and chronic disease/health (Renna 2007, Wolaver 2002, Williams, Powell, and Wechsler 2003); and state laws, taxes, policies and prices, e.g. state minimum legal drinking age, state beer taxes and alcohol prices (Williams 2005, Renna 2008, Bray 2005). 
We use the Australian price index of alcohol deflated using the all-good consumer price index (which varies by state of residence and year) as an instrument for alcohol consumption in this study (ABS 2011). A price index, defined as a normalised average of price relatives, compares how price relatives differ between time periods. According to the downwardsloping standard demand schedule, the demand for alcohol is inversely proportional to its price. There is a rich body of evidence in the literature showing that alcohol price is significantly correlated with alcohol consumption (Babor et al. 2010, Anderson, Chisholm, and Fuhr 2009, Bray 2005). In addition, since the variation in alcohol price index is not directly correlated with unobservable factors affecting individuals' antisocial behaviour participation, such as impulsiveness, risk-taking and sensation-seeking, once alcohol drinking pattern and other observables have been controlled for, the alcohol price index can be regarded as a valid instrument for the purpose of this study.

Another potential issue with our analysis is 'misclassification' with respect to the dichotomous binge variable. Misclassification refers to a response classified in the wrong category. As described in the previous section, the binge drinking variable is constructed from a survey question which asks respondents to report their drinking patterns in the last 12 months. Respondents had to then choose from a grid with the vertical array displaying the number of standard drinks such as "20 or more drinks", "11-19 standard drinks" to "less than 1 standard drink" or "none", and the horizontal array displaying the frequency such as "everyday", "5 to 6 days a week" to "about once a month", "less often" or "never" (see Figure A1). Given the complex structure of this question which involves a multitude of alternatives and a long recall period, the information used to construct the drinking pattern variable is more likely to be subject to misclassification error than if a straightforward and general question had been presented. In a discrete-response model, the misclassification of dependent variables renders coefficient estimates inconsistent when estimation techniques 
such as probit or logit are used. This has even more severe consequences in the multivariate probit system specification where the alcohol consumption variable is endogenous.

Note that one may also have similar concerns with regard to the other three dependent variables (i.e. antisocial behaviours). Given the long recall period (one year) and the antisocial and unlawful nature of these behaviours, responses relating to these behaviours are also likely to be misclassified. However, we do not explicitly account for misclassification for these for the following reasons. First, unlike the binge question, the behaviour-related survey question is quite straightforward and general. Second, the survey is anonymous and uses a drop-and-collect method which should significantly reduce the need for intentional mis-reporting. So we expect the degree of mis-reporting is lower than that for the binge question. Finally, further allowing for misclassification in the antisocial behaviours increases the complexity of the model substantially, given the need for numerically evaluating another four-dimensional integral. The maximisation of the likelihood failed in such an attempt.

A modified maximum likelihood approach proposed by Hausman, Abrevaya, and ScottMorton (1998) is employed to correct for potential misclassification of the binge drinking variable. This approach is further extended to dynamic discrete choice scenarios by Keane and Sauer (2009). Specifically, let $\tilde{Y}_{i, B}$ denote the true response for the underlying latent variable $Y_{i, B}^{*}$, i.e.

$$
\tilde{Y}_{i, B}=I\left(Y_{i, B}^{*}>0\right)
$$

where $I(E)$ is the indicator function equal to one if $E$ is true and zero otherwise. Following Hausman, Abrevaya, and Scott-Morton (1998), the probability of misclassification of the bingeing variable depends on the values of $\tilde{Y}_{i, B}$, and is assumed to be independent of the covariates and other dependent variables in the multivariate probit model. Accordingly, if 
$Y_{i, B}$ denotes the observed bingeing indicator variable, the misclassification probabilities can be defined as:

$$
\begin{aligned}
& \alpha_{0}=\operatorname{Pr}\left(Y_{i, B}=1 \mid \tilde{Y}_{i, B}=0\right), \\
& \alpha_{1}=\operatorname{Pr}\left(Y_{i, B}=0 \mid \tilde{Y}_{i, B}=1\right) .
\end{aligned}
$$

where $\alpha_{0}$ is the probability that a zero is misclassified as a one, and $\alpha_{1}$ is the probability that a one is misclassified as a zero.

Given a random sample of $N$ households, on the assumption that error terms in (2) follow a multivariate normal distribution, the system of equations can be consistently and efficiently estimated by maximising the following modified log-likelihood function that is corrected for misclassification:

$$
\begin{aligned}
& \sum_{i=1}^{N} \sum_{l=0}^{1} \sum_{m=0}^{1} \sum_{n=0}^{1} \sum_{k=0}^{1} d_{i, l m n k} \log \left\{P\left(\tilde{Y}_{i, B}=l, Y_{i, \text { Driving }}=m, Y_{i, \text { Disturbance }}=n, Y_{i, \text { Abuse }}=k \mid X_{i, B}, X_{i, \text { Driving }}, X_{i, \text { Disturbance }}, X_{i, A b u s e}\right) .\right. \\
& \left.\left(1-\alpha_{l}\right)+P\left(\tilde{Y}_{i, B}=1-l, Y_{i, \text { Driving }}=m, Y_{i, \text { Disturbance }}=n, Y_{i, \text { Abuse }}=k \mid X_{i, B}, X_{i, \text { Driving }}, X_{i, \text { Disturbance }}, X_{i, \text { Abuse }}\right) \cdot \alpha_{1-l}\right\}
\end{aligned}
$$

where $l, m, n$ and $k \in\{0,1\}, d_{i, l m n k}=I\left(\tilde{Y}_{i, B}=l, Y_{i, A S B 1}=m, Y_{i, A S B 2}=n, Y_{i, A S B 3}=k\right)$ and

$$
\begin{aligned}
& P\left(\tilde{Y}_{i, B}=l, Y_{i, \text { Driving }}=m, Y_{i, \text { Disturbance }}=n, Y_{i, \text { Abuse }}=k \mid X_{i, B}, X_{i, \text { Driving }}, X_{i, \text { Disturbance }}, X_{i, \text { Abuse }}\right) \\
& =\Phi_{4}\left[(2 l-1) X_{i, B}^{\prime} \hat{\beta}_{B},(2 m-1)\left(X_{i, \text { Driving }}^{\prime} \hat{\beta}_{\text {Driving }}+\hat{\alpha}_{\text {Driving }} l\right),(2 n-1)\left(X_{i, \text { Disturbance }}^{\prime} \hat{\beta}_{\text {Disturbance }}+\hat{\alpha}_{\text {Disturbance }} l\right),\right. \\
& \left.\quad(2 k-1)\left(X_{i, \text { Abuse }}^{\prime} \hat{\beta}_{\text {Abuse }}+\hat{\alpha}_{\text {Abuse }} l\right) ; \hat{\Sigma}\right],
\end{aligned}
$$

where 
$\hat{\Sigma}=\left(\begin{array}{cccc}1 & (2 l-1)(2 m-1) \hat{\rho}_{B, \text { Driving }} & (2 l-1)(2 n-1) \hat{\rho}_{B, \text { Disturbance }} & (2 l-1)(2 k-1) \hat{\rho}_{B, \text { Abuse }} \\ (2 l-1)(2 m-1) \hat{\rho}_{B, \text { Driving }} & 1 & (2 m-1)(2 n-1) \hat{\rho}_{\text {Driving,Disturbance }} & (2 m-1)(2 k-1) \hat{\rho}_{\text {Driving,Abuse }} \\ (2 l-1)(2 n-1) \hat{\rho}_{B, D \text { isturbance }} & (2 m-1)(2 n-1) \hat{\rho}_{\text {Driving, Disturbance }} & 1 & (2 n-1)(2 k-1) \hat{\rho}_{\text {Disturbance,Abuse }} \\ (2 l-1)(2 k-1) \hat{\rho}_{B, \text { Abuse }} & (2 m-1)(2 k-1) \hat{\rho}_{\text {Driving, Abuse }} & (2 n-1)(2 k-1) \hat{\rho}_{\text {Disturbance,Abuse }} & 1\end{array}\right)$,

and $\Phi_{4}(., \hat{\Sigma})$ is a four-variate standard normal cumulative distribution function (cdf) with the variance-covariance matrix $\hat{\Sigma}$. Hausman, Abrevaya, and Scott-Morton (1998) pointed out that the only assumption required for identification of this model (besides the usual condition that $E\left(X^{\prime} X\right)$ exists and is of full rank) is $\alpha_{0}+\alpha_{1}<1$. This implies that the classification problem cannot be so severe that respondents are misclassified more often than not, which is certainly a mild assumption.

Our system model is estimated using Stata 13. Since the estimation of the model involves evaluating a four-variate standard normal cdf, a recursive conditioning procedure known as the GHK smooth recursive probability simulator (Geweke 1989, Borsch-Supan and Hajivassiliou 1993, Keane 1994) is employed. The computation of marginal effects and treatment effects is complex given the endogenous structure of the model and the presence of common variables across the four equations. This results in joint and conditional probabilities that are highly non-linear functions of $X$, making analytical solutions of marginal effects and treatment effects difficult to obtain. We therefore estimate them in $\mathrm{R}$ via numerical derivatives of the multivariate normal distribution function with respect to the exogenous variables. Standard errors of the estimated marginal effects and treatment effects are computed by bootstrapping procedure wherein 500 new samples are randomly drawn with replacement. 


\section{Results}

\subsection{Correlation and Misclassification}

Tables 4 and 5 report the estimated parameters and corresponding standard errors of the MVP system model presented in Eqs. (1) - (3). We begin by examining pair-wise correlation coefficient estimates between the error terms in the four equations (Table 4). The correlations between the three antisocial behaviour equations are all statistically significant at the $1 \%$ level, suggesting that after controlling for observable individual characteristics and binge drinking, there are still significant common unobservable factors driving all three behaviours. Among these correlations, the one between Disturbance (created a public disturbance/nuisance, caused damage to property, or stole money, goods or property) and Abuse (verbally or physically abused someone) is the highest at 0.497 , which is consistent with intuition and observed correlations in Table A1. Interestingly and somewhat surprisingly, the correlations of the error terms in the binge equation and the antisocial behaviour equations are all small and statistically insignificant, suggesting a weak case for its endogeneity. This seems to suggest that common observable factors and binge drinking are the main sources of observed correlation between negative behaviours and binge in Table A1. There are no significant unobservable common factors that lead to the bingeing act and also lead to antisocial behaviours once binge drinking is explicitly controlled for in the behaviour equations.

The misclassification probability coefficient $\alpha_{1}$ is also statistically significantly different from zero at $1 \%$ significance level as seen in Table 5, justifying the need for addressing misclassification. This shows that there is a $9.9 \%$ chance of under-reporting when a respondent does not report bingeing but is in fact a binger. The estimate for coefficient $\alpha_{0}$ is 
statistically insignificant, so we do not find evidence for falsely reporting binge, or overreporting.

\subsection{Effect of bingeing on anti-social behaviours}

We report in the first row of Table 6 the average treatment effects of binge drinking on the alcohol-related antisocial behaviours. As expected, bingers are more likely to exhibit all three types of antisocial behaviours while under the influence of alcohol. In particular, bingers are more likely to drink and drive (14.4 percentage points [pp]), create a public disturbance/nuisance, cause damage to property, or steal money, goods or property (2.3 pp), and verbally or physically abuse someone ( $8.4 \mathrm{pp})$, while under the influence of alcohol. This is consistent with other studies which have found a strong association between drink-driving and binge drinking (see, for example, Quinlan et al. 2005) ${ }^{4}$.

In the case of linear seemingly unrelated regressions (SUR) model with normally distributed disturbances, it has been shown in Zellner (1962) that, when the equations have identical regressors or when a subset of regressors are omitted from a block of equations via exclusion restrictions, the multivariate maximum likelihood estimator is equivalent to a single equation OLS (or MLE) and there is no efficiency gain from a system estimation. Although what we have here is a non-linear system model that also involves an endogenous regressor on the right-hand side, it would be interesting to examine whether considering all three negative behaviours jointly in a system equation makes much difference from considering each behaviour separately. ${ }^{5}$ To investigate this, we estimate a separate bivariate probit model for each of the three antisocial behaviours with binge drinking as an endogenous treatment

\footnotetext{
${ }^{4}$ The model was re-run to the alternative definition of binge drinking, which only represents high-risk drinking pattern. The results show even higher ATEs of bingeing on antisocial behaviours under the influence of alcohol. Specifically, the ATEs of bingeing on Driving, Disturbance and Abuse respectively increase from $14.4 \mathrm{pp}$ to $17.0 \mathrm{pp}$, from $2.3 \mathrm{pp}$ to $4.2 \mathrm{pp}$ and from $8.4 \mathrm{pp}$ to $11.8 \mathrm{pp}$. Overall, the ATE of bingeing on any antisocial behaviour under the influence of alcohol increases from $25 \mathrm{pp}$ to $33 \mathrm{pp}$. The full results are available from the authors upon request.

${ }^{5}$ This is suggested by an anonymous referee.
} 
variable. The results of estimated coefficients and marginal effects are presented in Tables A4 - A9 in the supplementary online appendix. We can see that the estimated treatment effects of binge drinking on the respective antisocial behaviours from the three bivariate probit models are not very different (the differences are respectively $0.00 \%, 8.70 \%$ and $11.90 \%$ ) from those from the 4-equation multivariate probit in Table 6. The small difference for this application could be mainly due to computational differences as would be the case for a linear SUR model or due to the non-linearity of the model. It is also interesting to speculate whether the lack of evidence of endogeneity in this example contributes to similar results from the two approaches ${ }^{6}$.

\subsection{Demographic and socioeconomic effects}

Now, we turn towards the demographic and socioeconomic effects. Table 5 reports the estimated coefficients and corresponding standard errors for all exogenous variables. Whilst the coefficients are not very meaningful in probit models, they do indicate the direction of relationships with the latent dependent variables. For example, a negative coefficient on marital status across all four equations indicates that being married is negatively associated with the latent propensity to participate in antisocial behaviours and binge drinking. In general, the coefficients are statistically significant. More meaningful are the marginal effects in terms of probability changes rather than changes in the latent propensity. Due to the endogenous structure of the model and the presence of common variables, the marginal effect of an exogenous explanatory variable is computationally complex as it has a direct and an indirect component. Consider, for example, a common covariate $x$ that appears in all four

\footnotetext{
${ }^{6}$ The $10 \%$ significance level for the IV coefficient and marginal effect estimates in the bingeing equation, as shown in Tables 5 and 6-II, as well as in Tables A4-A9, raises concerns for potential weak instrument problem and for the identification of treatment effect on outcome variables. In fact, they all have p-values of around 0.07. A Stock and Yogo's (2005) weak IV test for linear IV models would not be appropriate as we have a non-linear model with a binary outcome variable and a binary treatment variable, and a weak instrument test for non-linear models is not yet available. However, our estimates for the ATEs of bingeing on all three antisocial behaviours are statistically highly significant, suggesting that there are most likely no serious issues of identification or biased estimates for the treatment effects. We thank an anonymous referee for bringing up this issue.
} 
equations. The total marginal effect of $x$ on, say, the probability of drink-driving comprises a direct effect of $x$ on the probability of drink-driving and an indirect effect through the effect of binge drinking (see, for example, Greene 2007). This indirect effect may either counter or reinforce the direct effect.

Tables 6-I and 6-II report the marginal effects of all exogenous variables in the model. The first column shows marginal effects on the probability of binge drinking while the remaining columns present marginal effects related to the three antisocial behaviours. Given the presence of an endogenous variable in each of the antisocial behaviour equations, the marginal effects comprise three components: direct, indirect and total effect. Most of the significant variables in Tables 6-I and 6-II have the expected signs. Age is a significant determinant in all four equations. To allow for a more flexible age profile for participation, we enter age bands (instead of continuous age) in the model. ${ }^{7}$ As expected, youth and young adults are more likely to engage in binge drinking and alcohol-related antisocial behaviours. For instance, compared to individuals aged over 60 which is the reference group, young adults (aged 23 to 29 ) are $62.5 \mathrm{pp}$ and $15.2 \mathrm{pp}$ more likely to exhibit binge drinking and drink driving, respectively. We find more or less similar age patterns for the antisocial behaviours Disturbance and Abuse, with the 12-29 age groups being more likely to engage in such activities.

It is interesting to note some of the contrasting findings relating to the direct and indirect effects across the same variables. Let us take the marginal effect of the 12-17 age group on the probability of drink driving as an example. Being in the 12-17 age group is associated with a $7.9 \mathrm{pp}$ lower probability of drink-driving, overall. This is a result of the $13.1 \mathrm{pp}$ lower direct effect of this age group on drink-driving (because of, say, being less likely to drive,

\footnotetext{
${ }^{7}$ A referee advised us to split the 12-29 age group into 12-17, 18-22, and 22-29 bands in view of the age restrictions on purchasing alcohol, driving a car and the zero-tolerance policies in early years of driving.
} 
being supervised driving or zero-tolerance driving restrictions in this young age group) being offset by a positive indirect effect of $5.1 \mathrm{pp}$ on drink driving via the binge drinking equation (because the 12-17 years old have a higher probability to binge and engage into antisocial behaviours). This highlights the advantage of our system model which addresses the endogeneity of binge drinking. Treating drinking pattern as exogenous and disregarding its indirect effect would have led to a larger negative effect of this age group on drink driving.

With regard to gender, males are significantly more likely to binge and participate in all three alcohol-related antisocial behaviours, with marginal effects ranging from $1.4 \mathrm{pp}$ for Disturbance, $3.4 \mathrm{pp}$ for Abuse, to $10.2 \mathrm{pp}$ for Driving. In terms of marital status, being married is associated with a lower probability of binge drinking and antisocial behaviours. We also observe some significant effects of household structure, race and remoteness on binge drinking and antisocial behaviours. Specifically, those coming from households with dependent children are less likely to binge and participate in antisocial behaviours. Being an aboriginal or Torres Strait islander is positively associated with binge drinking and anti-social behaviours under the influence of alcohol. Living in capital cities is associated with a significantly much lower probability of binge drinking and drink driving.

The effects of individuals' main occupation vary across binge drinking and the antisocial behaviours although we find a consistent association of unemployment status with most activities. Relative to those who are retired, on pension or engaged in home duties, both those who work and those who are unemployed are more likely to binge and more likely to drink and drive (Driving). While the effects on Disturbance (creating a public disturbance/nuisance, caused damage to property, or stole money, goods or property) are not statistically significant or only statistically significant at $10 \%$ significance level, we find that relative to the reference group, those who are unemployed are more likely, while those who study are less likely, to 
engage in activities such as verbally or physically abusing someone (Abuse). Where significant, unemployment status has the largest effect on the activities. Specifically, relative to the reference group, those who are unemployed are $7.9 \mathrm{pp}, 3.9 \mathrm{pp}, 0.4 \mathrm{pp}$ and $2.4 \mathrm{pp}$ more likely to binge and engage in Driving, Disturbance and Abuse, respectively, while under the influence of alcohol.

Education can be considered as a proxy for social class. Consistent with intuition, being educated is negatively related to binge drinking and antisocial behaviours such as Disturbance and Abuse. However, we find a significant positive association of education with drink driving. In particular, relative to those with less than year 12 qualifications, those who have a tertiary degree are $9.4 \mathrm{pp}, 0.4 \mathrm{pp}$ and $2.2 \mathrm{pp}$ less likely to engage in binge drinking, Disturbance and Abuse, respectively, but $2.6 \mathrm{pp}$ more likely to drink and drive (Driving).

Next, we look at the impact of income on binge drinking and the antisocial behaviours. The inclusion of both a linear and a quadratic term of the logarithm of household real income in the analysis allows for a more flexible effect of income on the probability of engaging into the four activities. A more sensible illustration of the impact of income is a plot of the predicted participation probabilities for the real income range covered by the sample. Figure 1 depicts the plots of the predicted probabilities for the four activities and corresponding $95 \%$ confidence intervals. Except for Driving, we find a U-shaped relationship between income and the other three activities, that is, individuals at both ends of the income distribution have higher probabilities of engaging in binge drinking, Disturbance and Abuse. In contrast, a slightly increasing income profile of Driving indicates that individuals with higher income are more likely to drink and drive.

Finally, we turn towards our price variable which we use as an instrument in the binge drinking equation. As expected, the marginal effect of price is negative and statistically 
significant. Specifically, a one percent increase from the mean of the aggregate real price will reduce the probability of binge drinking by $0.13 \mathrm{pp}$. Equivalently, evaluated at the sample mean, the marginal effect represents a participation elasticity of -0.30 . Note that probability elasticity represents a percentage change rather than an absolute change in drinking probability in response to a one percent change in price. Here, a price probability elasticity of -0.30 indicates that a one percent rise in the price index of alcohol will result in a 0.30 percent reduction in the probability of binge drinking. This indicates that the demand for alcohol is fairly inelastic to price which is consistent with previous studies. For instance, Gallet (2007) conducted an extensive meta-analysis of 132 studies which provide 1,172 estimated price elasticity observations for the consumption of beer, wine, spirits and alcohol. Across all the 263 elasticities reported for alcohol, the median elasticity was -0.49 .

Since the price variable only appears in the binge drinking equation, it has an indirect effect on the antisocial behaviours. Our results show that a $1 \%$ increase in the price index of alcohol will reduce drink driving probability by $0.11 \%$. A similar price increase will result in $0.10 \%$ and $0.18 \%$ reductions in the probability of Disturbance and Abuse, respectively. We also re-estimated the model using the price indices of three alcohol sub-categories, beer, wine and spirits, and our results are found to be quite robust. ${ }^{8}$

In summary, we also present in Table 7 the total marginal effects of the factors considered on the probability of participating in any one of the antisocial and unlawful behaviours. ${ }^{9}$ Our results indicate that youth and young adults, married individuals, being unemployed and being an aboriginal or Torres Strait islander, are positively associated with alcohol-related antisocial behaviours. On the other hand, having children at home and having higher education have a negative association with most of the anti-social behaviours. We also

\footnotetext{
${ }^{8}$ These results are available from the authors upon request.

${ }^{9}$ This is suggested by an anonymous referee.
} 
find a significant effect of price on binge drinking, and finally binge drinking has a significant effect on all three anti-social behaviours, with the higher impact on drink driving.

\section{Conclusion}

This paper uses a multivariate probit system model with a recursive structure and unit record data from the Australia National Drug Strategy Household Surveys to study the relationship between binge drinking and alcohol-related antisocial and unlawful behaviours, and the socio-economic and demographic determinants of such behaviours. Our modelling approach accommodates for the potential endogeneity of bingeing and the intrinsic correlation across all four alcohol-related negative behaviours via unobserved individual heterogeneity.

Interestingly, we do not find statistically significant evidence for binge drinking being endogenous in the determination of antisocial behaviours. Whilst bingeing significantly increases the probabilities of all three groups of negative behaviours as shown by the significant and positive treatment effects, its error term does not seem to be significantly correlated with the three other structural error terms once bingeing explicitly enters these equations. This result seems to suggest that unobservable factors such as personal traits that make a person binge are not strongly correlated with the remaining unobservable personal traits that subject the person to antisocial behaviours once common observable exogenous factors such as age profile and the act of binge itself are controlled.

Finally, we find strong evidence of common unobservable factors for all three antisocial and unlawful behaviours even after the act of binge drinking is explicitly controlled. Although there may or may not be an argument for considering each negative behaviour separately with a simpler model of bivariate probit in terms of estimating the slope 
coefficients, based on the results for the linear SUR models, our system model offers the extra benefit of quantifying the unobservable correlations among the different negative drinking behaviours. Such information can be useful for policy design in tackling negative drinking behaviours jointly via studying the joint and conditional probabilities, as illustrated in Ramful and Zhao (2008). Correlations of the unobservable factors between outcome variables in the linear SUR models can be easily obtained after estimating single equation OLS, but this is not the case for the nonlinear probit model here where the latent errors are not observable.

We also find strong evidence for a $9.9 \%$ probability of under-reporting for binge drinking, but no evidence for over-reporting. Due to the complexity of the data collection process for alcohol consumption, the potential for misclassification in binge drinking is addressed with a modified maximum likelihood function allowing for misreporting probabilities to be estimated explicitly.

Our results show that young adults (aged 18 to 29) are most likely among all age groups to be involved in binge drinking, drink driving, creating public disturbance/nuisance, stealing money, goods or property, or verbally or physically abusing someone while under the influence of alcohol. In terms of the total effect on the probabilities of negative behaviours, male, unmarried, unemployed, being less educated, and being aboriginal or Torres Strait islanders are more likely to be engaged in making disturbance and physical and verbal abusive behaviours.

Finally, we find that bingeing has a significant effect on increasing the probabilities for participating in all three negative alcohol related behaviours. Being highly intoxicated or committing the act of bingeing is shown to increase the probability of participating in any one of the antisocial and unlawful behaviours by $25 \mathrm{pp}$ (as shown in Table 8). This is a large 
effect considering the very low participation for such behaviours in the general drinking population. As most of the related costs from such negative drinking behaviours are often not considered in the bingers' private decision making but borne by the society, given the low risk of being charged criminally or incurring private health care costs, the results in this paper contribute to the evidence for the case for alcohol tax. Given any proposed alcohol tax reform often implies different implications to different alcohol beverages, further research towards quantifying the link to negative behaviours by differentiated beverage types would be useful to inform alcohol tax reforms. 
Table 1 Sample Participation in antisocial behaviours

for the Drinkers (per cent)

\begin{tabular}{lrrrr}
\hline & 2001 & 2004 & 2007 & 2010 \\
\hline Drove a motor vehicle & 13.11 & 12.75 & 12.11 & 11.35 \\
Created a public disturbance or nuisance & 2.39 & 2.27 & 2.12 & 1.91 \\
Caused damage to property & 1.39 & 1.28 & 1.21 & 1.10 \\
Stole money, goods or property & 0.50 & 0.35 & 0.33 & 0.32 \\
Verbally abused someone & 5.49 & 5.30 & 4.68 & 4.09 \\
Physically abused someone & 1.01 & 0.92 & 0.88 & 0.74 \\
\hline
\end{tabular}


Table 2 Sample Participation in aggregate antisocial behaviour groups

for the Drinkers conditioned on age, gender and year (per cent)

\begin{tabular}{|c|c|c|c|c|c|c|}
\hline Age group & & & 2001 & 2004 & 2007 & 2010 \\
\hline \multirow{7}{*}{$12-17$} & \multirow{4}{*}{ Male } & Driving & 8.00 & 4.95 & 4.70 & 3.52 \\
\hline & & Disturbance & 24.48 & 15.52 & 15.05 & 16.02 \\
\hline & & Abuse & 23.56 & 17.37 & 14.81 & 10.09 \\
\hline & & Driving & 4.20 & 3.60 & 2.28 & 4.15 \\
\hline & \multirow[t]{3}{*}{ Female } & Disturbance & 16.33 & 11.92 & 14.73 & 16.21 \\
\hline & & Abuse & 17.96 & 17.62 & 14.53 & 12.11 \\
\hline & & Driving & 29.73 & 28.73 & 22.74 & 21.59 \\
\hline \multirow{6}{*}{$18-22$} & \multirow[t]{3}{*}{ Male } & Disturbance & 29.30 & 25.20 & 25.78 & 20.58 \\
\hline & & Abuse & 31.68 & 29.32 & 26.00 & 20.94 \\
\hline & & Driving & 17.51 & 15.35 & 16.23 & 13.65 \\
\hline & \multirow[t]{3}{*}{ Female } & Disturbance & 11.39 & 10.72 & 10.09 & 9.60 \\
\hline & & Abuse & 15.49 & 17.68 & 15.63 & 14.00 \\
\hline & & Driving & 34.49 & 34.92 & 33.38 & 24.69 \\
\hline \multirow{6}{*}{$23-29$} & \multirow[t]{3}{*}{ Male } & Disturbance & 10.35 & 13.48 & 16.05 & 13.10 \\
\hline & & Abuse & 15.68 & 17.99 & 18.48 & 15.14 \\
\hline & & Driving & 17.22 & 18.02 & 16.52 & 15.15 \\
\hline & \multirow[t]{3}{*}{ Female } & Disturbance & 3.36 & 4.32 & 4.27 & 5.12 \\
\hline & & Abuse & 8.34 & 9.27 & 9.22 & 7.70 \\
\hline & & Driving & 27.73 & 30.33 & 25.09 & 24.40 \\
\hline \multirow{5}{*}{$30-39$} & \multirow[t]{3}{*}{ Male } & Disturbance & 2.94 & 4.34 & 4.65 & 3.56 \\
\hline & & Abuse & 8.47 & 10.03 & 9.20 & 7.43 \\
\hline & & Driving & 14.77 & 14.30 & 13.48 & 11.59 \\
\hline & \multirow[t]{3}{*}{ Female } & Disturbance & 1.00 & 1.61 & 1.11 & 1.53 \\
\hline & & Abuse & 4.70 & 4.72 & 4.40 & 4.30 \\
\hline \multirow{6}{*}{$40-49$} & & Driving & 25.48 & 26.11 & 22.17 & 21.00 \\
\hline & \multirow[t]{3}{*}{ Male } & Disturbance & 1.15 & 1.62 & 1.47 & 1.77 \\
\hline & & Abuse & 6.28 & 6.28 & 5.51 & 4.94 \\
\hline & & Driving & 15.07 & 14.82 & 12.74 & 10.55 \\
\hline & \multirow[t]{3}{*}{ Female } & Disturbance & 0.38 & 0.87 & 0.97 & 0.62 \\
\hline & & Abuse & 3.24 & 3.97 & 3.20 & 2.89 \\
\hline \multirow{6}{*}{$50-59$} & & Driving & 19.05 & 20.28 & 19.06 & 18.65 \\
\hline & \multirow[t]{3}{*}{ Male } & Disturbance & 0.58 & 1.05 & 0.95 & 0.82 \\
\hline & & Abuse & 4.58 & 3.27 & 4.06 & 3.32 \\
\hline & & Driving & 8.05 & 8.31 & 10.62 & 8.56 \\
\hline & \multirow[t]{3}{*}{ Female } & Disturbance & 0.24 & 0.30 & 0.24 & 0.43 \\
\hline & & Abuse & 1.65 & 1.46 & 2.16 & 1.98 \\
\hline \multirow{6}{*}{$60+$} & & Driving & 8.53 & 9.74 & 11.50 & 11.02 \\
\hline & \multirow[t]{3}{*}{ Male } & Disturbance & 0.15 & 0.25 & 0.09 & 0.22 \\
\hline & & Abuse & 1.36 & 1.34 & 1.49 & 1.38 \\
\hline & & Driving & 2.00 & 3.18 & 3.87 & 3.18 \\
\hline & \multirow[t]{2}{*}{ Female } & Disturbance & 0.00 & 0.10 & 0.05 & 0.08 \\
\hline & & Abuse & 0.48 & 0.45 & 0.50 & 0.44 \\
\hline
\end{tabular}

Notes: Driving: drove a motor vehicle; Disturbance: created a public disturbance/nuisance, caused damage to property, or stole money, goods or property; Abuse: verbally or physically abused someone. 
Table 3 Participation Rates by drinking patterns (Per cent)

\begin{tabular}{lcccc}
\hline & 2001 & 2004 & 2007 & 2010 \\
\hline Abstainer & 19.36 & 19.42 & 21.23 & 22.79 \\
Drinker & 80.64 & 80.58 & 78.77 & 77.21 \\
Binger & 34.77 & 35.95 & 31.63 & 30.61 \\
\hline Notes: Figures pertain to percentages out of the whole sample of a specific year. Data source: \\
NDSHS (2001-2010).
\end{tabular}

Table 4 Estimated correlation coefficients $\hat{\rho}$ from the Multivariate Probit Model

\begin{tabular}{lllll}
\hline & Driving & Disturbance & Abuse & Binge \\
\hline Driving & 1 & $0.283^{* * *}$ & $0.280^{* * *}$ & 0.004 \\
& & $(0.014)$ & $(0.011)$ & $(0.023)$ \\
Disturbance & 1 & $0.497^{* * *}$ & -0.074 \\
& & & $(0.011)$ & $(0.049)$ \\
Abuse & & 1 & -0.033 \\
& & & & $(0.034)$ \\
Binge & & & & 1 \\
\hline
\end{tabular}

Notes: Driving: drove a motor vehicle; Disturbance: created a public disturbance/nuisance, caused damage to property, or stole money, goods or property; Abuse: verbally or physically abused someone. Standard errors are given in parentheses. * Significant at $10 \%$; * Significant at $5 \% ; * * *$ Significant at $1 \%$. Standard errors are derived by bootstrapping procedure wherein 500 new samples are randomly drawn with replacement. 
Table 5 Results of Multivariate Model: Coefficients

\begin{tabular}{|c|c|c|c|c|c|c|c|c|}
\hline & \multicolumn{2}{|c|}{ Binge } & \multicolumn{2}{|c|}{ Driving } & \multicolumn{2}{|c|}{ Disturbance } & \multicolumn{2}{|r|}{ Abuse } \\
\hline & Coeff. & S.E. & Coeff. & S.E. & Coeff. & S.E. & Coeff. & S.E. \\
\hline Binge & & & 0.650 & $(0.035)^{* * *}$ & 0.998 & $(0.062)^{* * *}$ & 0.971 & $(0.051)^{* * *}$ \\
\hline Aged 12 to 17 & 0.900 & $(0.079)^{* * *}$ & -0.604 & $(0.076)^{* * *}$ & 1.937 & $(0.115)^{* * *}$ & 1.030 & $(0.072)^{* * *}$ \\
\hline Aged 18 to 22 & 1.781 & $(0.137)^{* * *}$ & 0.126 & $(0.041)^{* * *}$ & 1.731 & $(0.106)^{* * *}$ & 1.021 & $(0.059)^{* * *}$ \\
\hline Aged 23 to 29 & 1.574 & $(0.101)^{* * *}$ & 0.288 & $(0.033)^{* * *}$ & 1.391 & $(0.102)^{* * *}$ & 0.761 & $(0.053)^{* * *}$ \\
\hline Aged 30 to 39 & 1.176 & $(0.075)^{* * *}$ & 0.267 & $(0.030)^{* * *}$ & 0.981 & $(0.101)^{* * *}$ & 0.525 & $(0.050)^{* * *}$ \\
\hline Aged 40 to 49 & 0.843 & $(0.059)^{* * *}$ & 0.277 & $(0.029)^{* * *}$ & 0.656 & $(0.102)^{* * *}$ & 0.403 & $(0.049)^{* * *}$ \\
\hline Aged 50 to 59 & 0.434 & $(0.041)^{* * *}$ & 0.185 & $(0.027)^{* * *}$ & 0.452 & $(0.105)^{* * *}$ & 0.240 & $(0.048)^{* * *}$ \\
\hline Log of real income & -1.425 & $(0.213)^{* * * *}$ & -0.040 & $(0.189)$ & -0.572 & $(0.308)^{*}$ & -0.463 & $(0.237)^{*}$ \\
\hline $\begin{array}{l}\text { (Log of real } \\
\text { income })^{2}\end{array}$ & 0.080 & $(0.011)^{* * *}$ & 0.007 & $(0.009)$ & 0.026 & $(0.015)^{*}$ & 0.021 & $(0.012)^{*}$ \\
\hline With dependent & -0.149 & $(0.018)^{* * *}$ & -0.047 & $(0.016)^{* * *}$ & -0.148 & $(0.030)^{* * *}$ & -0.013 & $(0.022)$ \\
\hline Non dependent & -0.119 & $(0.024)^{* * *}$ & -0.098 & $(0.023)^{* * *}$ & -0.027 & $(0.042)$ & 0.057 & $(0.032)^{*}$ \\
\hline Year 2001 & -0.121 & $(0.057)^{* *}$ & 0.158 & $(0.019)^{* * *}$ & -0.061 & $(0.037)^{*}$ & 0.102 & $(0.027)^{* * *}$ \\
\hline Year 2004 & 0.006 & $(0.042)$ & 0.147 & $(0.018)^{* * *}$ & 0.002 & $(0.035)$ & 0.102 & $(0.026)^{* * *}$ \\
\hline Year 2007 & -0.037 & $(0.030)$ & 0.113 & $(0.019)^{* * *}$ & 0.041 & $(0.038)$ & 0.102 & $(0.028)^{* * *}$ \\
\hline Male & 0.277 & $(0.022)^{* * *}$ & 0.396 & $(0.014)^{* * *}$ & 0.449 & $(0.027)^{* * *}$ & 0.276 & $(0.019)^{* * *}$ \\
\hline Married & -0.289 & $(0.027)^{* * *}$ & -0.205 & $(0.016)^{* * *}$ & -0.268 & $(0.030)^{* * *}$ & -0.177 & $(0.023)^{* * *}$ \\
\hline Work & 0.185 & $(0.022)^{* * *}$ & 0.106 & $(0.021)^{* * *}$ & -0.083 & $(0.047)^{*}$ & -0.045 & $(0.031)$ \\
\hline Unemployed & 0.199 & $(0.047)^{* * *}$ & 0.128 & $(0.044)^{* * *}$ & 0.078 & $(0.074)$ & 0.194 & $(0.054)^{* * *}$ \\
\hline Studying & 0.020 & $(0.061)$ & 0.018 & $(0.059)$ & 0.009 & $(0.074)$ & -0.194 & $(0.065)^{* * *}$ \\
\hline Tertiary degree & -0.237 & $(0.028)^{* * *}$ & 0.181 & $(0.021)^{* * *}$ & -0.060 & $(0.043)$ & -0.159 & $(0.031)^{* * *}$ \\
\hline Diploma & -0.029 & $(0.018)$ & 0.089 & $(0.019)^{* * *}$ & -0.037 & $(0.037)$ & 0.005 & $(0.026)$ \\
\hline Year 12 & 0.003 & $(0.024)$ & 0.089 & $(0.024)^{* * *}$ & -0.012 & $(0.042)$ & -0.033 & $(0.032)$ \\
\hline Aboriginal or & 0.242 & $(0.065)^{* * *}$ & 0.067 & $(0.057)$ & 0.122 & $(0.084)$ & 0.317 & $(0.062)^{* * *}$ \\
\hline Living in capital & -0.187 & $(0.018)^{* * *}$ & -0.006 & $(0.014)$ & 0.012 & $(0.027)$ & 0.024 & $(0.020)$ \\
\hline Price of alcohol & -0.326 & $(0.180)^{*}$ & & & & & & \\
\hline Constant & 7.073 & $(1.440)^{* * * *}$ & -2.249 & $(0.969) * *$ & -0.460 & $(1.569)$ & -0.196 & $(1.205)$ \\
\hline$\alpha_{0}$ & 0.018 & $(0.019)$ & & & & & & \\
\hline$\alpha_{1}$ & 0.099 & $(0.020) * * *$ & & & & & & \\
\hline
\end{tabular}

Note: Driving: drove a motor vehicle; Disturbance: created a public disturbance/nuisance, caused damage to property, or stole money, goods or property; Abuse: verbally or physically abused someone. Standard errors are given in parentheses. * Significant at 10\%; ** Significant at $5 \%$; *** Significant at $1 \%$. Standard errors are derived by bootstrapping procedure wherein 500 new samples are randomly drawn with replacement. 
Table 6-I Results of Multivariate Model: Marginal effects-direct and indirect effects

\begin{tabular}{|c|c|c|c|c|c|c|c|c|c|c|}
\hline & \multirow{2}{*}{$\begin{array}{c}\text { P(Binge=1) } \\
\text { M.E. }\end{array}$} & \multicolumn{3}{|c|}{$\mathrm{P}($ Driving $=1)$} & \multicolumn{3}{|c|}{$\mathrm{P}($ Disturbance $=1)$} & \multicolumn{3}{|c|}{$\mathrm{P}($ Abuse $=1)$} \\
\hline & & D. $\bar{E}$. & I.E. & T.E & D.E. & I.E. & T.E & D.E. & I.E. & T.E \\
\hline Binge & & & & $\begin{array}{l}0.144 \\
(0.008)^{* * * *}\end{array}$ & & & $\begin{array}{l}0.023 \\
(0.002)^{* * *}\end{array}$ & & & $\begin{array}{l}0.084 \\
(0.006) * * *\end{array}$ \\
\hline Aged 12 to 17 & $\begin{array}{l}0.357 \\
(0.032) * * *\end{array}$ & $\begin{array}{l}-0.131 \\
(0.017)^{* * *}\end{array}$ & $\begin{array}{l}0.051 \\
(0.006)^{* * * *}\end{array}$ & $\begin{array}{l}-0.079 \\
(0.017)^{* * * *}\end{array}$ & $\begin{array}{l}0.051 \\
(0.002) * * *\end{array}$ & $\begin{array}{l}0.008 \\
(0.001)^{* * *}\end{array}$ & $\begin{array}{l}0.059 \\
(0.002)^{* * *}\end{array}$ & $\begin{array}{l}0.094 \\
(0.007)^{* * *}\end{array}$ & $\begin{array}{l}0.030 \\
(0.003)^{* * *}\end{array}$ & $\begin{array}{l}0.124 \\
(0.008) * * *\end{array}$ \\
\hline Aged 18 to 22 & $\begin{array}{l}0.707 \\
(0.055)^{* * * *}\end{array}$ & $\begin{array}{l}0.027 \\
(0.009) * * *\end{array}$ & $\begin{array}{l}0.102 \\
(0.01)^{* * * *}\end{array}$ & $\begin{array}{l}0.129 \\
(0.012)^{* * * *}\end{array}$ & $\begin{array}{l}0.046 \\
(0.002)^{* * * *}\end{array}$ & $\begin{array}{l}0.016 \\
(0.002) * * *\end{array}$ & $\begin{array}{l}0.062 \\
(0.002)^{* * * *}\end{array}$ & $\begin{array}{l}0.093 \\
(0.006) * * *\end{array}$ & $\begin{array}{l}0.059 \\
(0.007)^{* * * *}\end{array}$ & $\begin{array}{l}0.152 \\
(0.008) * * *\end{array}$ \\
\hline Aged 23 to 29 & $\begin{array}{l}0.625 \\
(0.040) * * *\end{array}$ & $\begin{array}{l}0.062 \\
(0.007) * * *\end{array}$ & $\begin{array}{l}0.090 \\
(0.008) * * *\end{array}$ & $\begin{array}{l}0.152 \\
(0.009)^{* * * *}\end{array}$ & $\begin{array}{l}0.037 \\
(0.002) * * *\end{array}$ & $\begin{array}{l}0.014 \\
(0.001)^{* * * *}\end{array}$ & $\begin{array}{l}0.051 \\
(0.002)^{* * * *}\end{array}$ & $\begin{array}{l}0.070 \\
(0.005) * * *\end{array}$ & $\begin{array}{l}0.052 \\
(0.005)^{* * * *}\end{array}$ & $\begin{array}{l}0.121 \\
(0.006) * * *\end{array}$ \\
\hline Aged 30 to 39 & $\begin{array}{l}0.467 \\
(0.030) * * *\end{array}$ & $\begin{array}{l}0.058 \\
(0.007) * * *\end{array}$ & $\begin{array}{l}0.067 \\
(0.006)^{* * * *}\end{array}$ & $\begin{array}{l}0.125 \\
(0.008) * * *\end{array}$ & $\begin{array}{l}0.026 \\
(0.002)^{* * * *}\end{array}$ & $\begin{array}{l}0.011 \\
(0.001)^{* * *}\end{array}$ & $\begin{array}{l}0.037 \\
(0.002)^{* * * *}\end{array}$ & $\begin{array}{l}0.048 \\
(0.005) * * *\end{array}$ & $\begin{array}{l}0.039 \\
(0.004)^{* * * *}\end{array}$ & $\begin{array}{l}0.087 \\
(0.005) * * *\end{array}$ \\
\hline Aged 40 to 49 & $\begin{array}{l}0.335 \\
(0.024)^{* * *}\end{array}$ & $\begin{array}{l}0.060 \\
(0.006)^{* * *}\end{array}$ & $\begin{array}{l}0.048 \\
(0.005)^{* * * *}\end{array}$ & $\begin{array}{l}0.108 \\
(0.007) * * *\end{array}$ & $\begin{array}{l}0.017 \\
(0.002) * * *\end{array}$ & $\begin{array}{l}0.008 \\
(0.001)^{* * *}\end{array}$ & $\begin{array}{l}0.025 \\
(0.002) * * *\end{array}$ & $\begin{array}{l}0.037 \\
(0.005)^{* * *}\end{array}$ & $\begin{array}{l}0.028 \\
(0.003) * * *\end{array}$ & $\begin{array}{l}0.065 \\
(0.005)^{* * *}\end{array}$ \\
\hline Aged 50 to 59 & $\begin{array}{l}0.172 \\
(0.016)^{* * * *}\end{array}$ & $\begin{array}{l}0.040 \\
(0.006) * * *\end{array}$ & $\begin{array}{l}0.025 \\
(0.003)^{* * * *}\end{array}$ & $\begin{array}{l}0.065 \\
(0.006)^{* * * *}\end{array}$ & $\begin{array}{l}0.012 \\
(0.003) * * *\end{array}$ & $\begin{array}{l}0.004 \\
(0) * * *\end{array}$ & $\begin{array}{l}0.016 \\
(0.002)^{* * *}\end{array}$ & $\begin{array}{l}0.022 \\
(0.004)^{* * * *}\end{array}$ & $\begin{array}{l}0.014 \\
(0.002) * * *\end{array}$ & $\begin{array}{l}0.036 \\
(0.005) * * *\end{array}$ \\
\hline Log of real income & $\begin{array}{l}-0.566 \\
(0.085)^{* * *}\end{array}$ & $\begin{array}{l}-0.009 \\
(0.041)\end{array}$ & $\begin{array}{l}-0.081 \\
(0.013)^{* * *}\end{array}$ & $\begin{array}{l}-0.090 \\
(0.043)^{* *}\end{array}$ & $\begin{array}{l}-0.015 \\
(0.008) *\end{array}$ & $\begin{array}{l}-0.013 \\
(0.002)^{* * *}\end{array}$ & $\begin{array}{l}-0.028 \\
(0.008)^{* * *}\end{array}$ & $\begin{array}{l}-0.042 \\
(0.022)^{*}\end{array}$ & $\begin{array}{l}-0.047 \\
(0.008) * * *\end{array}$ & $\begin{array}{l}-0.089 \\
(0.023) * * *\end{array}$ \\
\hline$(\log \text { of real income })^{2}$ & $\begin{array}{l}0.032 \\
(0.004)^{* * * *}\end{array}$ & $\begin{array}{l}0.002 \\
(0.002)\end{array}$ & $\begin{array}{l}0.005 \\
(0.001)^{* * * *}\end{array}$ & $\begin{array}{l}0.006 \\
(0.002) * * *\end{array}$ & $\begin{array}{l}0.001 \\
(0.000)^{*}\end{array}$ & $\begin{array}{l}0.001 \\
(0)^{* * * *}\end{array}$ & $\begin{array}{l}0.001 \\
(0) * * *\end{array}$ & $\begin{array}{l}0.002 \\
(0.001)^{*}\end{array}$ & $\begin{array}{l}0.003 \\
(0.000)^{* * * *}\end{array}$ & $\begin{array}{l}0.005 \\
(0.001)^{* * * *}\end{array}$ \\
\hline With dependent children & $\begin{array}{l}-0.059 \\
(0.007)^{* * * *}\end{array}$ & $\begin{array}{l}-0.010 \\
(0.004)^{* * *}\end{array}$ & $\begin{array}{l}-0.009 \\
(0.001)^{* * * *}\end{array}$ & $\begin{array}{l}-0.019 \\
(0.004)^{* * * *}\end{array}$ & $\begin{array}{l}-0.004 \\
(0.001)^{* * * *}\end{array}$ & $\begin{array}{l}-0.001 \\
(0) * * *\end{array}$ & $\begin{array}{l}-0.005 \\
(0.001)^{* * * *}\end{array}$ & $\begin{array}{l}-0.001 \\
(0.002)\end{array}$ & $\begin{array}{l}-0.005 \\
(0.001)^{* * * *}\end{array}$ & $\begin{array}{l}-0.006 \\
(0.002)^{* * * *}\end{array}$ \\
\hline Non dependent children & $\begin{array}{l}-0.047 \\
(0.010)^{* * * *}\end{array}$ & $\begin{array}{l}-0.021 \\
(0.005) * * *\end{array}$ & $\begin{array}{l}-0.007 \\
(0.001)^{* * * *}\end{array}$ & $\begin{array}{l}-0.028 \\
(0.005)^{* * * *}\end{array}$ & $\begin{array}{l}-0.001 \\
(0.001)\end{array}$ & $\begin{array}{l}-0.001 \\
(0) * * *\end{array}$ & $\begin{array}{l}-0.002 \\
(0.001)\end{array}$ & $\begin{array}{l}0.005 \\
(0.003) *\end{array}$ & $\begin{array}{l}-0.004 \\
(0.001)^{* * * *}\end{array}$ & $\begin{array}{l}0.001 \\
(0.003)\end{array}$ \\
\hline Year 2001 & $\begin{array}{l}-0.048 \\
(0.023)^{* *}\end{array}$ & $\begin{array}{l}0.034 \\
(0.004)^{* * *}\end{array}$ & $\begin{array}{l}-0.007 \\
(0.003)^{* *}\end{array}$ & $\begin{array}{l}0.027 \\
(0.005)^{* * *}\end{array}$ & $\begin{array}{l}-0.002 \\
(0.001)^{*}\end{array}$ & $\begin{array}{l}-0.001 \\
(0.001)^{* *}\end{array}$ & $\begin{array}{l}-0.003 \\
(0.001)^{* *}\end{array}$ & $\begin{array}{l}0.009 \\
(0.002) * * *\end{array}$ & $\begin{array}{l}-0.004 \\
(0.002)^{* *}\end{array}$ & $\begin{array}{l}0.005 \\
(0.003) *\end{array}$ \\
\hline Year 2004 & $\begin{array}{l}0.002 \\
(0.017)\end{array}$ & $\begin{array}{l}0.032 \\
(0.004)^{* * *}\end{array}$ & $\begin{array}{l}0.000 \\
(0.002)\end{array}$ & $\begin{array}{l}0.032 \\
(0.005)^{* * * *}\end{array}$ & $\begin{array}{l}0.000 \\
(0.001)\end{array}$ & $\begin{array}{l}0.000 \\
(0)\end{array}$ & $\begin{array}{l}0.000 \\
(0.001)\end{array}$ & $\begin{array}{l}0.009 \\
(0.002)^{* * *}\end{array}$ & $\begin{array}{l}0.000 \\
(0.001)\end{array}$ & $\begin{array}{l}0.010 \\
(0.003)^{* * *}\end{array}$ \\
\hline Year 2007 & $\begin{array}{l}-0.015 \\
(0.012)\end{array}$ & $\begin{array}{l}0.024 \\
(0.004)^{* * * *}\end{array}$ & $\begin{array}{l}-0.002 \\
(0.002)\end{array}$ & $\begin{array}{l}0.022 \\
(0.005)^{* * * *}\end{array}$ & $\begin{array}{l}0.001 \\
(0.001)\end{array}$ & $\begin{array}{l}0.000 \\
(0)\end{array}$ & $\begin{array}{l}0.001 \\
(0.001)\end{array}$ & $\begin{array}{l}0.009 \\
(0.003)^{* * * *}\end{array}$ & $\begin{array}{l}-0.001 \\
(0.001)\end{array}$ & $\begin{array}{l}0.008 \\
(0.003) * * *\end{array}$ \\
\hline Male & $\begin{array}{l}0.110 \\
(0.009) * * *\end{array}$ & $\begin{array}{l}0.086 \\
(0.003) * * *\end{array}$ & $\begin{array}{l}0.016 \\
(0.002)^{* * * *}\end{array}$ & $\begin{array}{l}0.102 \\
(0.004)^{* * * *}\end{array}$ & $\begin{array}{l}0.012 \\
(0.001)^{* * * *}\end{array}$ & $\begin{array}{l}0.002 \\
(0) * * *\end{array}$ & $\begin{array}{l}0.014 \\
(0.001)^{* * *}\end{array}$ & $\begin{array}{l}0.025 \\
(0.002)^{* * * *}\end{array}$ & $\begin{array}{l}0.009 \\
(0.001)^{* * * *}\end{array}$ & $\begin{array}{l}0.034 \\
(0.002) * * *\end{array}$ \\
\hline Married & $\begin{array}{l}-0.115 \\
(0.011)^{* * *}\end{array}$ & $\begin{array}{l}-0.044 \\
(0.004) * * *\end{array}$ & $\begin{array}{l}-0.017 \\
(0.002)^{* * *}\end{array}$ & $\begin{array}{l}-0.061 \\
(0.004)^{* * *}\end{array}$ & $\begin{array}{l}-0.007 \\
(0.001)^{* * *}\end{array}$ & $\begin{array}{l}-0.003 \\
(0) * * *\end{array}$ & $\begin{array}{l}-0.010 \\
(0.001)^{* * *}\end{array}$ & $\begin{array}{l}-0.016 \\
(0.002)^{* * *}\end{array}$ & $\begin{array}{l}-0.010 \\
(0.001)^{* * *}\end{array}$ & $\begin{array}{l}-0.026 \\
(0.002)^{* * *}\end{array}$ \\
\hline
\end{tabular}

Notes: M.E.: marginal effect; D.E.: direct effect; I.E.: indirect effect; T.E.: total effect; Driving: drove a motor vehicle; Disturbance: created a

goods or property; Abuse: verbally or physic 
Table 6-II Results of Multivariate Model: Marginal effects-direct and indirect effects (cont.)

\begin{tabular}{|c|c|c|c|c|c|c|c|c|c|c|}
\hline & \multirow{2}{*}{$\begin{array}{c}\mathrm{P}(\text { Binge }=1) \\
\text { M.E. }\end{array}$} & \multicolumn{3}{|c|}{$\mathrm{P}($ Driving $=1)$} & \multicolumn{3}{|c|}{$\mathrm{P}($ Disturbance $=1)$} & \multicolumn{3}{|c|}{$\mathrm{P}($ Abuse $=1)$} \\
\hline & & D. $\overline{\text { E. }}$ & I.E. & T.E & D. $\overline{\mathrm{E}}$. & I.E. & T.E & D. $\bar{E}$. & I.E. & T.E \\
\hline Work & $\begin{array}{l}0.073 \\
(0.009) * * *\end{array}$ & $\begin{array}{l}0.023 \\
(0.005) * * *\end{array}$ & $\begin{array}{l}0.011 \\
(0.001) * * *\end{array}$ & $\begin{array}{l}0.034 \\
(0.005) * * *\end{array}$ & $\begin{array}{l}-0.002 \\
(0.001) *\end{array}$ & $\begin{array}{l}0.002 \\
(0) * * *\end{array}$ & $\begin{array}{l}-0.001 \\
(0.001)\end{array}$ & $\begin{array}{l}-0.004 \\
(0.003)\end{array}$ & $\begin{array}{l}0.006 \\
(0.001) * * *\end{array}$ & $\begin{array}{l}0.002 \\
(0.003)\end{array}$ \\
\hline Unemployed & $\begin{array}{l}0.079 \\
(0.019) * * * *\end{array}$ & $\begin{array}{l}0.028 \\
(0.01)^{* * *}\end{array}$ & $\begin{array}{l}0.011 \\
(0.003) * * * *\end{array}$ & $\begin{array}{l}0.039 \\
(0.01)^{* * *}\end{array}$ & $\begin{array}{l}0.002 \\
(0.002)\end{array}$ & $\begin{array}{l}0.002 \\
(0)^{* * *}\end{array}$ & $\begin{array}{l}0.004 \\
(0.002)^{*}\end{array}$ & $\begin{array}{l}0.018 \\
(0.005)^{* * * *}\end{array}$ & $\begin{array}{l}0.007 \\
(0.002) * * * *\end{array}$ & $\begin{array}{l}0.024 \\
(0.005) * * *\end{array}$ \\
\hline Studying & $\begin{array}{l}0.008 \\
(0.024)\end{array}$ & $\begin{array}{l}0.004 \\
(0.013)\end{array}$ & $\begin{array}{l}0.001 \\
(0.004)\end{array}$ & $\begin{array}{l}0.005 \\
(0.013)\end{array}$ & $\begin{array}{l}0.000 \\
(0.002)\end{array}$ & $\begin{array}{l}0.000 \\
(0.001)\end{array}$ & $\begin{array}{l}0.000 \\
(0.002)\end{array}$ & $\begin{array}{l}-0.018 \\
(0.006) * * *\end{array}$ & $\begin{array}{l}0.001 \\
(0.002)\end{array}$ & $\begin{array}{l}-0.017 \\
(0.006) * * * *\end{array}$ \\
\hline Tertiary degree & $\begin{array}{l}-0.094 \\
(0.011)^{* * * *}\end{array}$ & $\begin{array}{l}0.039 \\
(0.005) * * *\end{array}$ & $\begin{array}{l}-0.014 \\
(0.002)^{* * *}\end{array}$ & $\begin{array}{l}0.026 \\
(0.005) * * *\end{array}$ & $\begin{array}{l}-0.002 \\
(0.001)\end{array}$ & $\begin{array}{l}-0.002 \\
(0) * * *\end{array}$ & $\begin{array}{l}-0.004 \\
(0.001) * * *\end{array}$ & $\begin{array}{l}-0.015 \\
(0.003) * * *\end{array}$ & $\begin{array}{l}-0.008 \\
(0.001)^{* * *}\end{array}$ & $\begin{array}{l}-0.022 \\
(0.003) * * * *\end{array}$ \\
\hline Diploma & $\begin{array}{l}-0.012 \\
(0.007)\end{array}$ & $\begin{array}{l}0.019 \\
(0.004) * * * *\end{array}$ & $\begin{array}{l}-0.002 \\
(0.001)\end{array}$ & $\begin{array}{l}0.018 \\
(0.004) * * * *\end{array}$ & $\begin{array}{l}-0.001 \\
(0.001)\end{array}$ & $\begin{array}{l}0.000 \\
(0)\end{array}$ & $\begin{array}{l}-0.001 \\
(0.001)\end{array}$ & $\begin{array}{l}0.000 \\
(0.002)\end{array}$ & $\begin{array}{l}-0.001 \\
(0.001)\end{array}$ & $\begin{array}{l}0.000 \\
(0.002)\end{array}$ \\
\hline Year 12 & $\begin{array}{l}0.001 \\
(0.010)\end{array}$ & $\begin{array}{l}0.019 \\
(0.005) * * *\end{array}$ & $\begin{array}{l}0.000 \\
(0.001)\end{array}$ & $\begin{array}{l}0.019 \\
(0.005) * * *\end{array}$ & $\begin{array}{l}0.000 \\
(0.001)\end{array}$ & $\begin{array}{l}0.000 \\
(0)\end{array}$ & $\begin{array}{l}0.000 \\
(0.001)\end{array}$ & $\begin{array}{l}-0.003 \\
(0.003)\end{array}$ & $\begin{array}{l}0.000 \\
(0.001)\end{array}$ & $\begin{array}{l}-0.003 \\
(0.003)\end{array}$ \\
\hline Aboriginal or Torres Strait origin & $\begin{array}{l}0.096 \\
(0.026) * * *\end{array}$ & $\begin{array}{l}0.015 \\
(0.012)\end{array}$ & $\begin{array}{l}0.014 \\
(0.004) * * *\end{array}$ & $\begin{array}{l}0.028 \\
(0.013)^{* *}\end{array}$ & $\begin{array}{l}0.003 \\
(0.002)\end{array}$ & $\begin{array}{l}0.002 \\
(0.001)^{* * *}\end{array}$ & $\begin{array}{l}0.005 \\
(0.002)^{* *}\end{array}$ & $\begin{array}{l}0.029 \\
(0.006)^{* * *}\end{array}$ & $\begin{array}{l}0.008 \\
(0.002) * * *\end{array}$ & $\begin{array}{l}0.037 \\
(0.006) * * *\end{array}$ \\
\hline Living in capital & $\begin{array}{l}-0.074 \\
(0.007)^{* * * *}\end{array}$ & $\begin{array}{l}-0.001 \\
(0.003)\end{array}$ & $\begin{array}{l}-0.011 \\
(0.001)^{* * *}\end{array}$ & $\begin{array}{l}-0.012 \\
(0.003) * * *\end{array}$ & $\begin{array}{l}0.000 \\
(0.001)\end{array}$ & $\begin{array}{l}-0.002 \\
(0)^{* * * *}\end{array}$ & $\begin{array}{l}-0.001 \\
(0.001)^{*}\end{array}$ & $\begin{array}{l}0.002 \\
(0.002)\end{array}$ & $\begin{array}{l}-0.006 \\
(0.001)^{* * * *}\end{array}$ & $\begin{array}{l}-0.004 \\
(0.002) * *\end{array}$ \\
\hline Price of alcohol drinks & $\begin{array}{l}-0.129 \\
(0.072)^{*}\end{array}$ & & $\begin{array}{l}-0.019 \\
(0.01)^{*}\end{array}$ & $\begin{array}{l}-0.019 \\
(0.01)^{*}\end{array}$ & & $\begin{array}{l}-0.003 \\
(0.002)^{*}\end{array}$ & $\begin{array}{l}-0.003 \\
(0.002)^{*}\end{array}$ & & $\begin{array}{l}-0.011 \\
(0.006)^{*}\end{array}$ & $\begin{array}{l}-0.011 \\
(0.006)^{*}\end{array}$ \\
\hline
\end{tabular}

goods or property; Abuse: verbally or physically abused someone. Standard errors are derived by bootstrapping procedure wherein 500 new samples are randomly drawn with replacement. * Significant at $10 \% ; * *$

Significant at 5\%; *** Significant at $1 \%$. 
Table 7 Results of Multivariate Model: Total marginal effects on the probability of any antisocial behaviour

\begin{tabular}{|c|c|c|}
\hline & \multicolumn{2}{|c|}{$\mathrm{P}($ any antisocial behaviour $=1)$} \\
\hline & M.E. & S.E. \\
\hline Binge & 0.251 & $(0.012 * * *)$ \\
\hline Aged 12 to 17 & 0.104 & $(0.021)^{* * * *}$ \\
\hline Aged 18 to 22 & 0.343 & $(0.018)^{* * * *}$ \\
\hline Aged 23 to 29 & 0.325 & $(0.014)^{* * *}$ \\
\hline Aged 30 to 39 & 0.248 & $(0.011)^{* * *}$ \\
\hline Aged 40 to 49 & 0.198 & $(0.010)^{* * * *}$ \\
\hline Aged 50 to 59 & 0.117 & $(0.009)^{* * *}$ \\
\hline Log of real income & -0.207 & $(0.054)^{* * *}$ \\
\hline$(\text { Log of real income })^{2}$ & 0.012 & $(0.003)^{* * *}$ \\
\hline With dependent children & -0.030 & $(0.005)^{* * *}$ \\
\hline Non dependent children & -0.029 & $(0.007)^{* * *}$ \\
\hline Year 2001 & 0.030 & $(0.008)^{* * *}$ \\
\hline Year 2004 & 0.042 & $(0.007) * * *$ \\
\hline Year 2007 & 0.031 & $(0.006)^{* * *}$ \\
\hline Male & 0.150 & $(0.005)^{* * *}$ \\
\hline Married & -0.096 & $(0.005)^{* * *}$ \\
\hline Work & 0.035 & $(0.006) * * *$ \\
\hline Unemployed & 0.067 & $(0.013)^{* * *}$ \\
\hline Studying & -0.012 & $(0.016)$ \\
\hline Tertiary degree & 0.000 & $(0.007)$ \\
\hline Diploma & 0.016 & $(0.005)^{* * *}$ \\
\hline Year 12 & 0.016 & $(0.007)^{* *}$ \\
\hline Aboriginal or Torres Strait Islander origin & 0.071 & $(0.016)^{* * *}$ \\
\hline Living in capital & -0.017 & $(0.004)^{* * *}$ \\
\hline Price of alcohol drinks & -0.032 & $(0.018)^{*}$ \\
\hline
\end{tabular}

Notes: M.E.: marginal effect; Standard errors are derived by bootstrapping procedure wherein 500 new samples are randomly drawn with replacement. $*$ Significant at $10 \%$; $*$ Significant at $5 \%$; *** Significant at $1 \%$. 
Figure 1: Income effect on Binge Drinking, Driving, Disturbance and Abuse
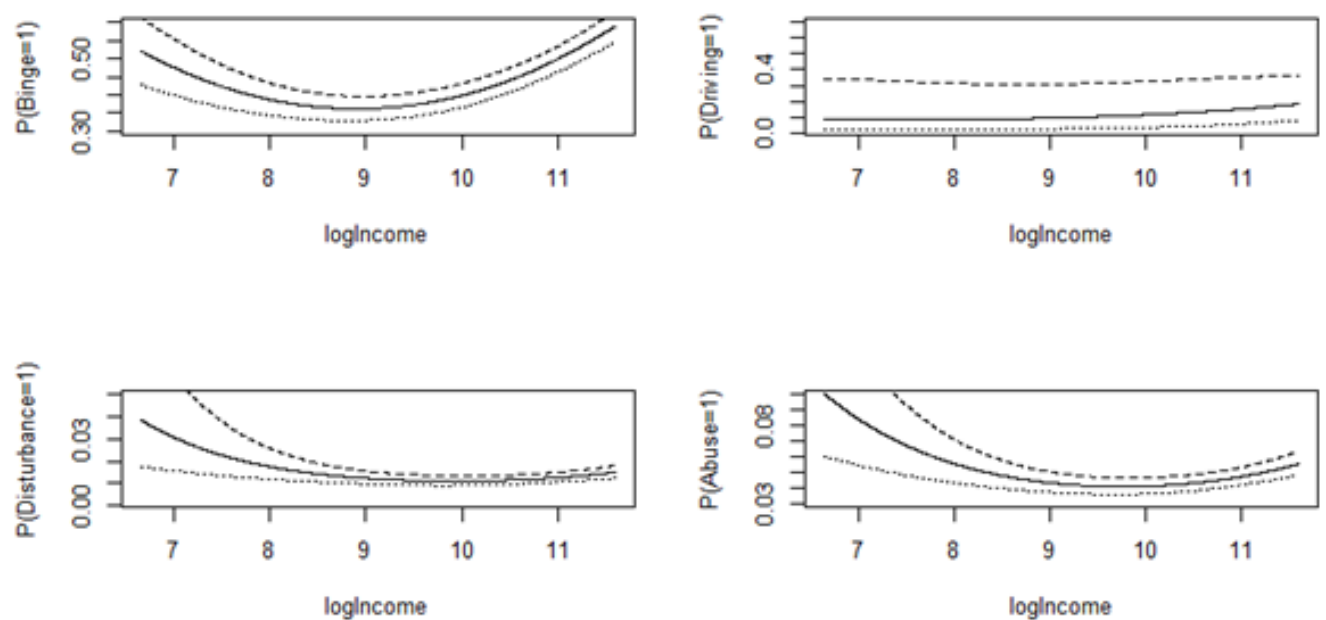

- $95 \%$ upper bound

.... $95 \%$ lower bound

Note: Driving: drove a motor vehicle; Disturbance: created a public disturbance/nuisance, caused damage to property, or stole money, goods or property; Abuse: verbally or physically abused someone. 


\section{References}

BS. 2011. 6401.0 - Consumer Price Index, Australia. Canberra.

AIHW. 2011. 2010 National Drug Strategy Household Survey Report. Canberra.

Anderson, P., D. Chisholm, and D. C. Fuhr. 2009. "Effectiveness and Cost-Effectiveness of Policies and Programmes to Reduce the Harm Caused by Alcohol." Lancet 373 (9682): 2234-46.

Babor, T. F., R. Caetano, S. Casswell, G. Edwards, N. Giesbrecht, K. Graham, J. Grube, et al. 2010. Alcohol: No Ordinary Commodity. Research and Public Policy. Second Ed. London: Oxford University Press.

Beck, Kenneth H., James C. Fell, and Alice F. Yan. 2009. “A Comparison of Drivers with High versus Low Perceived Risk of Being Caught and Arrested for Driving under the Influence of Alcohol." Traffic Injury Prevention 10 (4): 321-319.

Begg, S., T. Vos, B. Barker, C. Stevenson, L. Stanley, and A. Lopez. 2007. The Burden of Disease and Injury in Australia 2003. BULLETIN-WORLD. Cat. no. P. Canberra: Australian Institute of Health and Welfare.

Bègue, Laurent, Philippe Arvers Claudine Pérez-Diaz, Baptiste Subra, Emmanuelle Ceaux, Sebastian Roché Véronique Aurélie Bricout, Joel Swendsen, and Michel Zorman. 2012. "The Role of Alcohol Consumption in Female Victimization: Findings from a French Representative Sample." Substance Use \& Misuse 47 (1): 1-11.

Borsch-Supan, A., and V.A. Hajivassiliou. 1993. "Smooth Unbiased Multivariate Probability Simulators for Maximum Likelihood Estimation of Limited Dependent Variable Models." Journal of Econometrics 58 (3). Elsevier: 347-68.

Bray, J. W. 2005. “Alcohol Use, Human Capital, and Wages.” Journal of Labor Economics 23 (2): 279-312.

Brown, Jennifer L, and Peter a Vanable. 2007. "Alcohol Use, Partner Type, and Risky Sexual Behavior among College Students: Findings from an Event-Level Study." Addictive Behaviors 32 (12): 2940-52.

Chaloupka, Frank J, and Henry Wechsler. 1996. "The Impact of Price, Availability, and Alcohol Control Policies on Binge Drinking in College.” Contemporary Economic Policy 14 (4): 112-24.

Chatterji, Pinka, Daval Dave, Robert Kaestner, and Sara Markowitz. 2004. "Alcohol Abuse and Suicide Attempts among Youth.” Economics and Human Biology 2 (2): 159-80.

Cherpitel, C. J. 1993. "Alcohol, Injury, and Risk-Taking Behavior: Data from a National Sample." Alcoholism, Clinical and Experimental Research 17 (4): 762-66.

1995. "Alcohol and Casualties: Comparison of County-Wide Emergency Room Data with the County General Population.” Addiction 90 (3): 343-50.

Douglas, K A, J L Collins, C Warren, L Kann, R Gold, S Clayton, J G Ross, and L J Kolbe. 1997. "Results from the 1995 National College Health Risk Behavior Survey." Journal of American College Health 46 (2): 55-66.

Fagrell, B, U De Faire, and S Bondy. 1999. "The Effects of Light to Moderate Drinking on 
Cardiovascular Diseases." Journal of Internal Medicine 246 (4): 331-40.

Freebairn, John. 2010. "Special Taxation of Alcoholic Beverages to Correct Market Failures." Economic Papers 29 (2): 200-214.

French, M. T., and J. C. Maclean. 2006. "Underage Alcohol Use, Delinquency, and Criminal Activity." Health Economics 15 (12): 1261-81.

French, M. T., and I. Popovici. 2011. "That Instrument Is Lousy! In Search of Agreement When Using Instrumental Variables Estimation in Substance Use Research.” Health Economics 20 (2): $127-46$.

Gallet, C A. 2007. "The Demand for Alcohol: A Meta-Analysis of Elasticities." Australian Journal of Agricultural and Resource Economics 51 (2): 121-35. doi:10.1111/j.1467-8489.2007.00365.x.

Gaziano, JM, JE Buring, and JL Breslow. 1993. "Moderate Alcohol Intake, Increased Levels of HighDensity Lipoprotein and Its Subfractions, and Decreased Risk of Myocardial Infarction." The New England Journal of Medicine 329 (25): 1829-34.

Geweke, J. 1989. "Bayesian Inference in Econometric Models Using Monte Carlo Integration." Econometrica 57 (6): 1317-39.

Gottfredson, Michael R, and Travis Hirschi. 1990. A General Theory of Crime. Edited by Francis Cullen and Robert Agnew. Criminological Theory Past to Present. Vol. 34. Stanford University Press.

Greene, W. H. 2007. "Chapter 23 Models for Discrete Choice.” In Econometric Analysis, 6th ed., 770-862. Prentice Hall Upper Saddle River, NJ.

Greenfield, T K, and C Weisner. 1995. "Drinking Problems and Self-Reported Criminal Behavior, Arrests and Convictions: 1990 US Alcohol and 1989 County Surveys." Addiction 90 (3): 361-73.

Hausman, J. A., J. Abrevaya, and F. M. Scott-Morton. 1998. "Misclassification of the Dependent Variable in a Discrete-Response Setting.” Journal of Econometrics 87 (2): 239-69.

Hayashi, F. 2000. Econometrics. Princeton University Press.

Keane, M. P., and R. M. Sauer. 2009. "Classification Error in Dynamic Discrete Choice Models: Implications for Female Labor Supply Behavior.” Econometrica 77 (3): 975-91.

Keane, M.P. 1994. “A Computationally Practical Simulation Estimator for Panel Data.” Econometrica 62 (1): $95-116$.

Koch, S. F., and K. A. McGeary. 2005. "The Effect of Youth Alcohol Initiation on High-School Completion.” Economic Inquiry 43 (4): 750-65.

Lane, Tim, Starley B. Shade, James McIntyre, and Stephen F. Morin. 2008. "Alcohol and Sexual Risk Behavior among Men Who Have Sex with Men in South African Township Communities." AIDS and Behavior 12 (1): 78-85.

Li, C., D.S. Poskitt, and X. Zhao. 2014. Partial Identification of Treatment Effect in Binary Outcome Models with Endogenous Treatment - an Application to Effect of Health Insurance on Dental Visits. 
Maddala, G.S. 1983. Limited Dependent and Qualitative Variables in Econometrics. Cambridge, UK: Cambridge University Press.

Malinski, MK, HD Sesso, F. Lopez-Jimenez, JE Buring, and JM Gaziano. 2004. “Alcohol Consumption and Cardiovascular Disease Mortality in Hypertensive Men." Archives of Internal Medicine 164 (6): 623-28.

Manning, W., E. Keeler, J. Newhouse, E. Sloss, and J. Wasserman. 1989. "The Taxes of Sin. Do Smokers and Drinkers Pay Their Way?" Journal of the American Medical Association 261 (11): 1604-9.

Markowitz, Sara, Robert Kaestner, and Michael Grossman. 2005. "An Investigation of the Effects of Alcohol Consumption and Alcohol Policies on Youth Risky Sexual Behaviors." Alcohol 95 (2). National Bureau of Economic Research Cambridge, Mass., USA: 263-66.

Monfardini, Chiara, and Rosalba Radice. 2008. "Testing Exogeneity in the Bivariate Probit Model: A Monte Carlo Study." Oxford Bulletin of Economics and Statistics 70 (2): 271-82.

NHMRC. 2001. Australia Alcohol Guidelines: Health Risks and Benefits. Canberra. . 2009. Australian Guidelines to Reduce Health Risks from Drinking Alcohol. Canberra: Commonwealth of Australia.

Petrie, Dennis J., Christopher M. Doran, Anthony P. Shakeshaft, and Rob Sanson-Fisher. 2010. “The Relationship between Risky Alcohol Consumption, Crime and Traffic Accidents in Australian Rural Communities." Addictive Behaviors 35 (4): 359-62.

Quinlan, K.P., R.D. Brewer, P. Siegel, D.A. Sleet, A.H. Mokdad, R.A. Shults, and N. Flowers. 2005. "Alcohol-Impaired Driving among US Adults, 1993-2002." American Journal of Preventive Medicine 28 (4): 346-50.

Ramful, Preety, and Xueyan Zhao. 2008. "Individual Heterogeneity in Alcohol Consumption: The Case of Beer, Wine and Spirits in Australia.” Economic Record 84 (265): 207-22.

Renna, F. 2007. "The Economic Cost of Teen Drinking: Late Graduation and Lowered Earnings." Health Economics 16 (4): 407-19.

-2008. “Teens' Alcohol Consumption and Schooling." Economics of Education Review 27 (1): 69-78.

Richardson, J., and S. Crowley. 1997. "Taxation to Minimise the Social and Economic Cost of Alcohol Consumption.” In Taxation Towards 2000, edited by J. Head and R. Krever, 176-96. Australian Tax Research Foundation, Conferences Series No. 19, Sydney.

Rimm, EB. 1996. "Alcohol Consumption and Coronary Heart Disease: Good Habits May Be More Important than Just Good Wine.” American Journal of Epidemiology 143: 1094-98.

Salomé, Helena J, Michael T French, Helen Matzger, and Constance Weisner. 2005. "Alcohol Consumption, Risk of Injury, and High-Cost Medical Care." The Journal of Behavioral Health Services \& Research 32 (4): 368-80.

Sen, Bisakha. 2002. "Does Alcohol-Use Increase the Risk of Sexual Intercourse among Adolescents? Evidence from the NLSY97." Journal of Health Economics 21 (6): 1085-93. 
Srivastava, P, and Xueyan Zhao. 2010. "What Do the Bingers Drink? Micro-Unit Evidence on Negative Externalities and Drinker Characteristics of Alcohol Consumption by Beverage Types." Economic Papers 29 (2): 229-50.

Stock, J. H., and M. Yogo. 2005. “Testing for Weak Instruments in Linear IV Regression.” In Identification and Inference for Econometric Models, edited by Donald W. K. Andrews, 80-108. New York: Cambridge University Press. doi:citeulike-article-id:1459542.

Umana, Joseph E. Olufunmilayo I. Fawole, and Ikeola A. Adeoye. 2014. "Prevalence and Correlates of Intimate Partner Violence towards Female Students of the University of Ibadan, Nigeria." BMC Women's Health 14 (1): 131.

Wechsler, H, A Davenport, G Dowdall, B Moeykens, and S Castillo. 1994. "Health and Behavioral Consequences of Binge Drinking in College. A National Survey of Students at 140 Campuses." The Journal Of The American Medical Association 272 (21). US: American Medical Assn: 1672-77.

Weiser, Sheri D, Karen Leiter, Michele Heisler, Willi McFarland, Fiona Percy-de Korte, Sonya M DeMonner, Sheila Tlou, Nthabiseng Phaladze, Vincent Iacopino, and David R Bangsberg. 2006. "A Population-Based Study on Alcohol and High-Risk Sexual Behaviors in Botswana." Edited by Michael Farrell. PLoS Medicine 3 (10). Public Library of Science: 1940-48.

Williams, J. 2005. "Habit Formation and College Students' Demand for Alcohol." Health Economics 14 (2): 119-34.

Williams, J., F. J. Chaloupka, and H. Wechsler. 2002. "Are There Differential Effects of Price and Policy on College Students' Drinking Intensity?” Contemporary Economic Policy 23 (1). Blackwell Synergy: 78-90.

Williams, J., L. M. Powell, and H. Wechsler. 2003. "Does Alcohol Consumption Reduce Human Capital Accumulation? Evidence from the College Alcohol Study." Applied Economics 35 (10): 1227-39.

Wolaver, A. M. 2002. "Effects of Heavy Drinking in College on Study Effort, Grade Point Average, and Major Choice." Contemporary Economic Policy 20 (4): 415-28.

Zellner, A. 1962. "An Efficient Method of Estimating Seemingly Unrelated Regressions and Tests of Aggregation Bias.” Journal of American Statistical Association 57 (298): 348-68.

Zetola, Nicola M., Chawangwa Modongo, Bisayo Olabiyi, Doreen Ramogola-Masire, Ronald G. Collman, and Li-Wei Chao. 2014. "Examining the Relationship between Alcohol Use and HighRisk Sex Practices in a Population of Women with High HIV Incidence despite High Levels of HIV-Related Knowledge.” Sexually Transmitted Infections, sextrans - 2013. 